\title{
Financial well-being among Malaysian manufacturing employees
}

\author{
Shiau Wei Chan ${ }^{a^{*}}$, Siti Sarah Omar ${ }^{\mathrm{a}}$ and Wen Lik Yonga
}

${ }^{a}$ Faculty of Technology Management and Business, Universiti Tun Hussein Onn Malaysia, 86400 Batu Pahat, Johor, Malaysia

\section{CHRON I C L E}

Article history:

Received: November 26, 2017

Received in revised format: January 31,2018

Accepted: April 7, 2018

Available online:

April 7, 2018

Keywords:

Financial Well-being

Manufacturing

Employees

\section{A B S T R A C T}

\begin{abstract}
Employees and financial well-being are two aspects that are closely related to each other, and have been deeply studied by researchers. Not only can financial well-being directly affect an individual, but it can also indirectly affect his/her organization as well as employer. Any level of financial employees' well-being, either low or high, will change their job performance. Thus, the purpose of this study is to determine the level of financial well-being among manufacturing employees in Batu Pahat, as well as to test the relationships between determinants and financial well-being among manufacturing employees in Batu Pahat. In this study, seven research hypotheses were developed to examine seven determinants, including age, income, gender, education, current job position, income, and marital status which influence employees' financial well-being. In this study, 220 employees at the production level were selected randomly from a manufacturing company in Batu Pahat, Johor, Malaysia. Then, a questionnaire was distributed to the employees. The data obtained were analyzed quantitatively using SPSS version 22.0. The results of this study revealed that the level of financial well-being was moderate and all of the determinants were positively related to financial well-being among the manufacturing employees. This quantitative study is important to the manufacturing industry in Malaysia in order to gain insight on the correlation between financial well-being and its determinants.
\end{abstract}

C) 2018 by the authors; licensee Growing Science, Canada

\section{Introduction}

Owing to the consequences of the financial crisis in the past few years, financial well-being has been raised significantly as a part of an individual's life skill and has drawn attention to both employers and employees. Currently, in Malaysia, many individuals, especially the young generation find it hard to keep up with payments and price inflation. This is due to lack of financial literacy that helps them avoid spending beyond their limits. The majority of young employees in Malaysia earn a monthly salary of below than RM1,000, while 21 percent earn between RM1,000 and RM1,500. In other words, 88 percent of young workers in Malaysia earn below RM1,500, in which they are not able to pay their payments and debt with any extra savings. Owning a credit card can be convenient but also a problem at the same time. Little to no spending discipline can result in excess credit card bill debt and poor credit ratings, which would affect financial well-being planning in the future. The result of poor financial literacy in an individual's life may raise a lot of unwanted life issues and financial problems which disturb the order of an individual's life (Rahim et al., 2016). Earlier research has found that poor job 
performance is affected by the level of employees' financial well-being (Mokhtar et al., 2015). Therefore, employers have a role to play in encouraging employees to improve their financial well-being as financially strained employees will drag down the performance of the companies or agencies(Rahim et al., 2016). Financial well-being is one of the well-being elements besides career, physical, social, and community aspects (Rath \& Harter, 2010).

As great financial well-being and a healthy lifestyle are increasingly gaining people's attention today, the increasingly globalized capital market gives different kinds of financial products and investment funds as significant choices in achieving people's personal financial objectives (Malaysia Financial Planning Council, 2004). There are different factors which could influence on well-being such as higher standards for life expectations, uncertainty in lifestyle, commitments, and stress. An employee's financial well-being maintains a significant relationship with employee's productivity (Zaimah et al., 2013). Poor financial information may also influence on employees' financial well-being, including managing their wealth and securing a comfortable retirement plan. In addition, the low level of basic financial concepts may be linked to the lack of retirement planning and lack of wealth at the end of an individual's life. Other than that, poor financial management and stress will affect the employees' financial well-being (Delafrooz \& Paim, 2011; Sabri et al., 2010).

Mokhtar et al. (2015) focused on financial well-being among public employees in Malaysia, there was no affinitive conclusion pertaining the manufacturing industry. Meanwhile, Rahim et al. (2016) focused on the financial adequacy of public sector employees which did not cover the financial well-being among manufacturing employees. Therefore, it is important for this study to focus on this topic to fill the gaps in previous research. On the other hand, most of the previous studies focused on the relationship between financial literacy, financial well-being and financial concern (Taft et al., 2013), as well as the financial well-being of Malaysian college students (Fazli Sabri et al., 2012) where different variables were used. Thus, studies focusing on the financial well-being of manufacturing employees are limited. In addition, there is a lack of related studies conducted in Malaysia. Thus, there is a need to

conduct a study on the financial well-being of manufacturing employees and to test the relationships between the determinants of financial well-being of manufacturing employees in Batu Pahat.

\section{Literature Review}

Financial well-being refers to the unseen notion that is used to describe the financial background or status of an individual or a family (Mokhtar et al., 2015). A group's socioeconomic and demographic determinants tend to influence the level of financial well-being of individuals. The socioeconomic and demographic determinants include gender, education level, race, current job position, income, marital status, and age. Previous study found that age, income, and education were positively related to financial well-being (Joo, 1998; O'Neill, 1995; Porter \& Garman, 1993). The research also found that those who are older, are married, and have higher education and high-income level possess higher levels of financial well-being. Researchers have reported that several factors appear to influence financial wellbeing. Among the most common factors are demographic and socioeconomic characteristics such as gender, marital status, education, ethnicity, age, income, and home ownership.

The first determinant of financial well-being is age. Old citizens aged 75 years old and above are most likely to feel happy about their current financial well-being, while those aged 18 to 64 years old feel less positive. For instance, those 75 year olds and above feel that the money they earn is sufficient and they are satisfied with their lives. They have more than enough money to do what they want and have extra money to use. They are also the only ones indicating that they are free from financial problem and financial stress. However, the group aged between 50 and 64 is a group of people that are nearly retired and always less positive than those who are younger rather than those who are older than them. Although they have sufficient money to do anything they would like to, but as for matching the views of the group aged 18- to 49-year-olds, they seem less positive than the $52 \%$ of those aged 75 and older 
who say the same. Meanwhile, those aged 18 to 64 are struggling the most with their current financial well-being. A new report based on data from the Gallup-Health Well-Being Index found that American adults over the age of 55 rank higher on measures of well-being than the rest of the population, with individuals over the age of 75 faring the best. Older Americans scored high in financial well-being, where 52 percent are thriving, versus 32 percent among those younger than 55 .

Many progresses have already been done in the past in Malaysia to downsize the gender gap, as stated by Ahmad (1998), in both absolute and relative aspects for women's development in the country. Different genders will show various results in terms of financial activities and the level of financial wellbeing, which is essential to study during college. Moreover, different gender after graduation and fulfillment of life changed their financial well-being substantially when compared to the time during study. The level of financial well-being of female students is normally higher that the level of male students. Different socialization indicate that the levels of female and male's financial well-being are not the same. Past experiences are recognized as the main factor influencing the differences in behavior both among sociologists (e.g. Bandura) and consumer researchers (Fishbein, 2007). The total population of Malaysia is about 28.3 million. Within the population, 91.8 percent are Malaysian citizens while 8.2 percent are non-citizens coming from foreign countries. Malaysia is made up of 3 large ethnic groups: Malays (67.4\%), Chinese (24.6\%), and Indians (7.3\%), with the rest made up of other races $(0.7 \%)$. Due to different races and ethnics along with their own culture and traditions, each group's financial spending and habits are different, whereby it is mostly determined by family culture and ethnical habits of spending. All the three main races are included in the study to see if the level of financial well-being of different races is greatly related to each other.

The next determinant is the respondent's level of education. For instance, the level of education will increase the yearly income of both men and women averagely. Unfortunately, the education premium of men is a bit lower than women. Services under education include production and consumption which have social benefits. Education not only entails studies and the ability to learn as well as the proficiency gained by him or her, but also includes concerns about what can be created from the capabilities contributed to the society. Therefore, the society should contribute to education investments. The education social return using conventional methods cannot estimate all of education's social benefits and costs. Financial literacy and financial well-being have been predicted using academic ability in a number of studies (Sabri et al., 2010). Normally, a student's academic discipline and his/her ability to adapt something new and apply new information are reflected by a higher GPA, and include the ability to function well outside of family within a community system. Thus, these capabilities increase the chances that individuals will learn successful financial management.

Current job position is another vital factor in determining financial well-being. Bhushan and Medury (2013) mentioned that employees will be financially affected by the level of employment. For example, Worthington and Whittaker (2006) also discovered that businessmen, professionals, farm owners, and traders have a high level of financial literacy and financial well-being. Due to different job position levels, employees behave differently to themselves according to their own identities outside the organization. An employee's job position symbolizes a person's social class level accordingly. This makes people more confident by spending more on outlook and being more materialistic. A policymaker's understanding of income and financial well-being can be found based on the true relationship of integration at the objective income level and the subjective well-being. The financial well-being of a person, especially the elderly can be improved with a higher income level. In a multivariate context, wealth and debt seem to have strong effects on financial well-being, with it being equal in size to that of income.

Few studies have attempted to link individual differences in pay valence to marital status and few have pointed to marital status as a factor that might affect workers' comparison standards for the purposes of financial well-being. This lack of attention to marital status and to other family characteristics as 
well may reflect the most pressing interest of many researchers in identifying the effects of job and organization features that managers can change. Researchers have repeatedly found that married men earn higher wages than unmarried men, even when education and work experience are controlled. Studies investigating the effect of marital status on women's earnings are less conclusive (Greenhalgh, 1980), but those based on recent data found that married women enjoy an earning advantage as well (Waldfogel, 1997). Moreover, married men receive better performance ratings than unmarried men. For instance, individual productivity is usually understood as a function of ability and effort. Thus, if married individuals are more productive, it may be because they are more talented and skilled, or it may be because they work harder and deliberately seek out ways to perform better. A variety of research findings suggest that married workers indeed engage in greater effort. Married individuals report devoting more effort to their work (Bielby \& Bielby, 1988). Married people engage in bigger efforts, which are directed towards activities that yield in higher pay which means that they possess various attitudes towards their work, pay, and finances. Married workers may view money as more important than unmarried workers do. Besides, married workers may also feel less satisfied with their current financial circumstances, and therefore be more motivated to take steps to increase their earnings. In this study, the independent variables used as determinants include gender, age, race, education level, job position, income, and marital status. Meanwhile, the dependent variable is financial well-being. Seven hypotheses have been constructed based on the results from the previous research:

H1: There is a relationship between age and financial well-being.

$\mathrm{H} 2$ : There is a relationship between gender and financial well-being.

H3: There is a relationship between race and financial well-being.

$\mathrm{H} 4$ : There is a relationship between education level and financial well-being.

H5: There is a relationship between job position and financial well-being.

H6: There is a relationship between income and financial well-being.

H7: There is a relationship between marital status and financial well-being.

\section{Methodology/Materials}

\subsection{Research Design}

According to Sekaran (2006), research is a process of answering solutions to a problem after deep finding and analysis. This research uses the quantitative method to collect numerical data from the interested population. Basic statistics such as percentage, frequency, mean, and standard deviation are then analyzed to explain a particular phenomenon. Correlation study is a study that is specifically used to reveal the possible relationship between the vital factors of the independent variables and the problem of the dependent variable. Quantitative research explains phenomena by gathering numerical data that are analyzed based on mathematically-based methods (Gunderson \& Aliaga, 2005). Quantitative research is implemented in this study since it is an appropriate method to determine the level of financial well-being and detect the relationships between the chosen determinants and financial well-being among manufacturing employees in Batu Pahat. The data collected were analyzed quantitatively using SPSS.

\subsection{Respondents}

Sampling is a very important element in doing a research study, especially in a large study population. Sampling can represent a large population in a study, hence it is used in this study. The sample size is determined based on Krejcie and Morgan (1970) table. Random samples are samples in which each unit in the population has an equal chance of being selected (Krathwohl, 1998). In this study, the targeted population was 400 production operators, administrative employees, executives, and managers in the manufacturing industry in Batu Pahat, Johor. A total number of 220 printed questionnaires were distributed to one of the manufacturing companies in Batu Pahat. Although 220 questionnaires were 
sent, only 196 questionnaire were collected back from the respondents for this research. As a result, the response rate was $89.1 \%$.

\subsection{Instrumentation}

This study was carried out using a survey method as the tool for gathering data. The questionnaire was made up of two sections. The first section in the questionnaire gathered the respondents' demographic information, while the second section gathered data on the level of financial well-being. The second section was measured using a five-point Likert Scale ranging from $5=$ very high until $1=$ very low. When a respondent answers the questionnaire, they have to specify their level of agreement or disagreement on a symmetric agree-disagree scale for a series of statements. A pretest was distributed to 30 employees in the manufacturing industry. The Cronbach's Alpha value for this questionnaire is 0.888 which is slightly more than 0.7 , the standard value. According to Hair, Black, Babin, Anderson, and Tatham (2006), it is an agreeable and valid questionnaire.

\subsection{Data Analysis}

The data gathered from the respondents were analyzed using a tool called Statistical Package for Social Science (SPSS) version 22.0. SPSS is a computer software that helps in managing and analyzing large numbers of data by creating fast and accurate results in the form of tables and graphical charts. Descriptive analysis was used to further investigate the data in order to describe the data and characteristics of the population or phenomenon being studied (Neuman, 2013). Other than that, SPSS is also able to show graphical reports in the form of charts, graphs, and tables, as well as giving the standard deviation, percentage, and ranking of all the data inserted. The data generated were used to examine the demographic characteristics of employees in the manufacturing industry. Cramer's V method is normally used to find out the level of correlation in between variables. Cramer's $\mathrm{V}$ has a minimum value of 0 and a maximum value of 1 . If the Cramer's $\mathrm{V}$ value lies near to 0 , then there is a weak correlation between the variables, whereas if the value lies near to 1, it is said that the correlation is strong between the variables (Sekaran, 2006).

\section{Results and Findings}

\subsection{Level of Financial Well-being}

Table 1 shows the mean score of the respondents' financial well-being. From the average mean score, it can be concluded that the level of financial well-being of respondents is still at the medium level (average mean=3.27). Most of the respondents tend to have a moderate level of financial well-being, and out of 196 respondents, only a few of them have a low level of financial well-being. From the list of financial well-being questions listed in Table 1, the highest mean score is 3.73 from the question "How sure are you that you will have enough money to provide for a comfortable old age?" On the other hand, the lowest mean score question is "How often do you have trouble paying monthly bills (electricity, telephone, instalment, credit cards)?" which is only 2.78 . As compared to the study by Mokhtar et al. (2015), these two questions were totally different with this research in terms of target industry and employees. This indicates that the manufacturing employees in Batu Pahat feel more confident on their retirement plan with their salary and savings plan during their older age. But they were more worried about the individual payments by the end of the month. 


\section{Table 1}

Mean Score for Financial Well-being

\begin{tabular}{|c|c|c|c|}
\hline No. & Questions & Mean & Interpretation \\
\hline 1 & Your satisfaction level towards your overall financial situations & 3.19 & Medium \\
\hline 2 & How worried are you about your personal finances today? & 3.38 & Medium \\
\hline 3 & How well off are you financially & 2.89 & Medium \\
\hline 4 & Which of the following best describe your current financial situation & 3.24 & Medium \\
\hline 5 & How do you feel about your current financial well-being & 3.36 & Medium \\
\hline 6 & $\begin{array}{l}\text { How sure are you that you will have enough money to provide for a comfort- } \\
\text { able old age }\end{array}$ & 3.73 & Medium \\
\hline 7 & How often does your last pay run out before the next pay day & 3.24 & Medium \\
\hline 8 & $\begin{array}{l}\text { How often do you have trouble paying monthly bills (electricity, telephone, } \\
\text { instalment, credit cards) }\end{array}$ & 2.78 & Medium \\
\hline 9 & How confident are you that you have control over your personal finances & 3.04 & Medium \\
\hline 10 & Your confidences are you that you know how to manage personal finances & 3.21 & Medium \\
\hline 11 & $\begin{array}{l}\text { How easy would it be for you to get money to pay a financial emergency that } \\
\text { cost RM } 1000\end{array}$ & 3.47 & Medium \\
\hline \multirow[t]{2}{*}{12} & How worried are you about your personal finances in general & 3.62 & Medium \\
\hline & Average Score & 3.27 & Medium \\
\hline
\end{tabular}

\subsection{Relationships between determinants and financial well-being}

In this study, the researcher used Cramer's V method to further analyze the correlations that exist between the determinants (age, gender, race, job, education level, marital status, and income) and the financial well-being of manufacturing employees in Batu Pahat. Each of the determinants were analyzed accordingly to see the value of Cramer's V. There will be a strong relationship if the Cramer's V value is greater than 0.25 . If the calculated value is less than 0.25 , it is considered as a weak relationship. Table 2 demonstrates the summary of correlation tested using Cramer's V analysis as well as the result of hypothesis testing, which is whether they are accepted or rejected according to their value of Cramer's V.

\section{Table 2}

Summary of Hypothesis Result and Correlation

\begin{tabular}{lcc}
\hline \multicolumn{1}{c}{ Hypothesis } & Cramer's V Value & Result \\
\hline $\mathrm{H}_{1}$ : There is a relationship between gender and financial well-being & 0.358 & accepted \\
$\mathrm{H}_{2}$ : There is a relationship between age and financial well-being & 0.391 & accepted \\
$\mathrm{H}_{3}$ : There is a relationship between race and financial well-being & 0.326 & accepted \\
$\mathrm{H}_{4}$ : There is a relationship between education level and financial well-be- & 0.422 & accepted \\
$\mathrm{H}_{5}$ : There is a relationship between job position and financial well-being & 0.304 & accepted \\
$\mathrm{H}_{6}$ : There is a relationship between income and financial well-being & 0.316 & accepted \\
$\mathrm{H}_{7}$ : There is a relationship between marital status and financial well-being & 0.441 & accepted \\
\hline
\end{tabular}

As shown in Table 2, the relationships of all of the variables with financial well-being were accepted in this research as their Cramer's V values were greater than 0.25. Among the hypotheses, the highest Cramer's V value recorded is 0.441 . The value means that the determinant "marital status" has the strongest relationship with financial well-being compared to the other determinants. This indicates that being single or married among the manufacturing employees in Batu Pahat can affect their level of financial well-being (Baek \& DeVaney, 2004; Joo \& Grable, 2004). However, the current job position has the lowest Cramer's V value among all the determinants, which is 0.304 . In other words, it has the weakest relationship with financial well-being. 


\section{Conclusion}

In summary, the findings indicate that the financial well-being among manufacturing employees in Batu Pahat, Johor, Malaysia is at a medium level. Besides, the determinants (age, gender, race, job, education level, marital status, and income) were positively correlated to financial well-being. Generally, manufacturing employees' financial well-being can be enhanced through the help of the employers. Employers are recommended to help reduce employees' financial trouble and indirectly, help reduce the financial stress of employees to strengthen their financial well-being in the future. Financial education at the workplace is a great way to establish proper financial concepts and financial knowledge in the employees. It is beneficial for both employers and employees to have a win-win situation, as the past studies mentioned that the financial well-being of an employee has an impact on the productivity of the employee, as well as the performance of the organization. This kind of study can be conducted in other different industries to contribute more useful knowledge for both employers and employees.

\section{Acknowledgement}

This work was supported by Universiti Tun Hussein Onn Malaysia under Grant No. U431.

\section{References}

Ahmad, A. (1998). Country briefing paper: Women in Malaysia. Asian Development Bank.

Baek, E., \& DeVaney, S. A. (2004). Assessing the baby boomers' financial wellness using financial ratios and a subjective measure. Family and Consumer Sciences Research Journal, 32(4), 321-348.

Bhushan, P., \& Medury, Y. (2013). Financial literacy and its determinants. International Journal of Engineering, Business and Enterprise Applications, 4(2), 155-160.

Bielby, D. D., \& Bielby, W. T. (1988). She works hard for the money: Household responsibilities and the allocation of work effort. American journal of Sociology, 93(5), 1031-1059.

Delafrooz, N., \& Paim, L. H. (2011). Determinants of financial wellness among Malaysia workers. African Journal of Business Management, 5(24), 10092.

Fazli Sabri, M., Cook, C. C., \& Gudmunson, C. G. (2012). Financial well-being of Malaysian college students. Asian Education and Development Studies, 1(2), 153-170.

Fishbein, M. (2007). Prediction and change of health behavior: Applying the reasoned action approach: Psychology Press.

Greenhalgh, C. (1980). Male-female wage differentials in Great Britain: Is marriage an equal opportunity? The Economic Journal, 90(360), 751-775.

Gunderson, B., \& Aliaga, M. (2005). Interactive statistics: Upper Saddle River, NJ: Prentice Hall.

Hair, J., Black, W., Babin, B., Anderson, R., \& Tatham, R. (2006). Multivariate Data Analisys, Prantice-Hall: Inc.

Joo, S.-h. (1998). Personal financial wellness and worker job productivity.

Joo, S.-h., \& Grable, J. E. (2004). An exploratory framework of the determinants of financial satisfaction. Journal of family and economic Issues, 25(1), 25-50.

Krathwohl, D. R. (1998). Methods of educational and social science research . Long Grove, IL: Waveland Press, Inc.

Krejcie, R. V., \& Morgan, D. W. (1970). Determining sample size for research activities. Educational and psychological measurement, 30(3), 607-610.

Malaysia Financial Planning Council, M. (2004). RFP Module 1-Fundamentals of Financial Planning: MFPC, Kuala Lumpur.

Mokhtar, N., Husniyah, A., Sabri, M., \& Talib, M. A. (2015). Financial well-being among public employees in Malaysia: A preliminary study. Asian Social Science, 11(18), 49.

Neuman, W. L. (2013). Social research methods: Qualitative and quantitative approaches: Pearson education. 
O'Neill, B. M. (1995). Characteristics and practices of financially-stressed homeowners in Prince William county, Virginia. Virginia Tech.

Porter, N. M., \& Garman, E. T. (1993). Testing a conceptual model of financial wellbeing. Financial Counseling and Planning, 4, 135-164.

Rahim, H. A., Othman, M. A., Sabri, M. F., \& Jusoh, Z. M. (2016). Influential Predictors for Financial Adequacy Among Malaysian Public Sector Employees. Australian Journal of Business and Economic Studies, 2(1).

Rath, T., \& Harter, J. K. (2010). Wellbeing: The five essential elements: Simon and Schuster.

Sabri, M. F., MacDonald, M., Hira, T. K., \& Masud, J. (2010). Childhood consumer experience and the financial literacy of college students in Malaysia. Family and Consumer Sciences Research Journal, 38(4), 455-467.

Sekaran, U. (2006). Research Methods of Business. Canada: Jonh Wiley \& Sons: Inc.

Taft, M. K., Hosein, Z. Z., \& Mehrizi, S. M. T. (2013). The relation between financial literacy, financial wellbeing and financial concerns. International Journal of Business and Management, 8(11), 63.

Waldfogel, J. (1997). The effect of children on women's wages. American sociological review, 209217.

Worthington, R. L., \& Whittaker, T. A. (2006). Scale development research: A content analysis and recommendations for best practices. The Counseling Psychologist, 34(6), 806-838.

Zaimah, R., Masud, J., Haron, S. A., Othman, M., Awang, A. H., \& Sarmila, M. (2013). Financial wellbeing: Financial ratio analysis of married public sector workers in Malaysia. Asian Social Science, 9(14), 1.

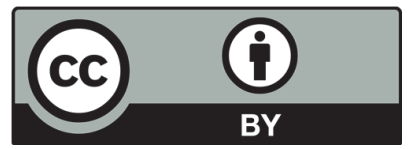

(C) 2018 by the authors; licensee Growing Science, Canada. This is an open access article distributed under the terms and conditions of the Creative Commons Attribution (CC-BY) license (http://creativecommons.org/licenses/by/4.0/). 